\title{
COMPARAÇÃO DOS ESTRESSORES PSICOSSOCIAIS, BEM-ESTAR NO TRABALHO E COPING ENTRE OS TRABALHADORES DO ATENDIMENTO PRÉ-HOSPITALAR TERRESTRE E AÉREO
}

\author{
Mônica Beatriz Ortolan LIBARDI ${ }^{1}$; Ângela Ferreira BARROS²; Alessandra da Rocha \\ ARRAIS $^{3}$; Carlos Manoel Lopes RODRIGUES ${ }^{4}$
}

\section{RESUMO}

Introdução: a atuação dos profissionais do atendimento pré-hospitalar (APH), tanto do serviço terrestre quanto aéreo, muitas vezes ocorrem em locais perigosos de difícil acesso, expostos a diferentes condições ambientais, suscetíveis a acidentes e à violência urbana e expõe esses trabalhadores a riscos psicossociais com possíveis repercussões na saúde física e mental. Justificativa: essa exposição ocupacional tem sido estudada, porém poucos estudos compararam esses riscos entre os profissionais atuantes no serviço terrestre e aéreo. Objetivo: comparar o bem-estar no trabalho, estressores psicossociais e coping nos trabalhadores atuantes no APH terrestre e aéreo. Métodos: estudo transversal quantitativo com trabalhadores atuantes no APH público do Distrito Federal (DF). Aplicados instrumento sociodemográfico, Escala dos Estressores Psicossociais no Contexto Laboral (EEPCL), Inventário de Bem-Estar no Trabalho (IBET) e Escala de Coping Ocupacional (ECO). Na análise dos dados, aplicado o teste t de student e software Statistical Package for Social Science (SPSS). Considerada significância estatística quando $\mathrm{p}<0,05$. Resultados: amostra composta por 585 participantes, representando $81 \%$ da população estimada. Dentre os participantes, 56 (9,8\%) também trabalhavam no Serviço Aeromédico que apresentaram maiores escores na avaliação de satisfação no trabalho. Os demais fatores das escalas e dimensão do inventário não apresentaram distinções entre os dois grupos. Conclusões: a diferença identificada no nível de satisfação no trabalho pode indicar diferenças nas condições de trabalho específicas de cada grupo, incluindo grau de especialização. A existência de recompensas simbólicas deve ser incluída em estudos futuros.

Palavras-chave: Estresse ocupacional, Satisfação no Trabalho, Serviços Médicos de Emergência.

Extraído da defesa de Mestrado intitulada "Questões de gênero nos estressores psicossociais, bem-estar no trabalho e coping dos trabalhadores do atendimento pré-hospitalar" ocorrida em maio de 2019 na Escola Superior de Ciências da Saúde/Fundação de Ensino e Pesquisa em Ciências da Saúde.

\section{Introdução}

O Atendimento Pré-Hospitalar (APH) é o atendimento emergencial em ambiente fora do hospital, têm o objetivo de estabilizar e/ou imobilizar a vítima e removê-la o mais rápido possível com segurança, para a unidade de saúde de

1. Enfermeira, Mestre. Mestrado Profissional em Ciências para a Saúde, Serviço de Atendimento Móvel de Urgência do Distrito Federal E-mail: monicab.libardi@gmail.com

2. Enfermeira, Doutora. Mestrado Profissional em Ciências para a Saúde, Escola Superior de Ciências da Saúde. Brasília, Distrito Federal. E-mail: anbarros@yahoo.com.br

3. Psicóloga, Pós Doutora. Mestrado Profissional em Ciências para a Saúde, Escola Superior de Ciências da Saúde. Brasília, Distrito Federal. E-mail: alearrais@gmail.com

4. Psicólogo, Doutorando. Programa de Pós-Graduação em Psicologia Social, do Trabalho e das Organizações, Universidade de Brasília. Brasília, Distrito Federal. E-mail: prof.carlos.manoel@gmail.com 


\section{CON

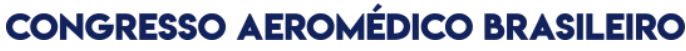

referência (BRASIL, 2006).

Em virtude da necessidade de se prestar um atendimento de emergência mais ágil e de percorrer longas distâncias, foram criados os Serviços Aeromédicos (SA), no qual atuam trabalhadores do APH do Corpo de Bombeiro Militar (CBM) e Serviço de Atendimento Móvel de Urgência (SAMU).

No APH os trabalhadores vivenciam riscos psicossociais como o estresse, elevada tensão ambiental e imposição de uma rotina intensa (LEITE et al, 2016) acrescido de aspectos nocivos desse tipo de atividade que muitas vezes ocorrem em locais perigosos como relevo declivoso de difícil acesso, aglomerados e rodovias (DIAS et al, 2016), podendo acarretar inclusive riscos a terceiros e à pacientes, o que mobiliza sentimentos negativos no trabalhador, podendo levá-lo ao sofrimento (LIMA, SOUSA, 2015) e ao adoecimento.

No serviço aeromédico, os trabalhadores vivenciam riscos adicionais como o risco de queda da aeronave, maior demanda de treinamentos específicos e do cumprimento de protocolos. Porém poucos estudos analisaram os efeitos dessas peculiaridades para os trabalhadores (LESZCZYNSKI et al, 2019).

Diante disso, o objetivo foi comparar o bem-estar no trabalho, estressores psicossociais e coping entre os trabalhadores atuantes no APH terrestre e aéreo.

\section{Metodologia}

Esse estudo foi extraído da pesquisa intitulada: "O bem estar no trabalho, estratégias de coping, exposição aos fatores de riscos e estressores psicossociais no atendimento pré-hospitalar e as implicações das questões de gênero", aprovado no Comitê de Ética da Fundação de Ensino e Pesquisa em Ciências da Saúde pelo no parecer: 2.565.525.

Foi realizado estudo transversal quantitativo com trabalhadores atuantes no APH do Distrito Federal, composto por profissionais do Corpo de Bombeiros e do Serviço de Atendimento Móvel de Urgência do Distrito federal. Foram incluídos trabalhadores do APH há, no mínimo, seis meses. A coleta de dados ocorreu entre maio e julho de 2018. Os participantes responderam a um questionário sociodemográfico, a Escala dos Estressores Psicossociais no Contexto Laboral (EEPCL) (FERREIRA et al, 2015), o Inventário de Bem-Estar no Trabalho (IBET) (SIQUEIRA et al, 2014) e a Escala de Coping Ocupacional (ECO) (PINHEIRO et al, 2003). 


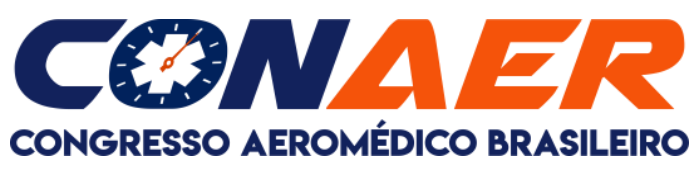

Os participantes foram divididos em dois grupos conforme o local de atuação, sendo um grupo com os trabalhadores atuantes somente nos serviços terrestres e o outro grupo com atuação também no serviço aeromédico.

$\mathrm{Na}$ análise dos dados foi realizada a distribuição em frequência absoluta e relativa das variáveis qualitativas e medidas de tendência central e dispersão das variáveis quantitativas. Para avaliar as diferenças entre os trabalhadores do serviço terrestre e aéreo, foi aplicado o teste t de student, quando apropriado. Foi considerada significância estatística quando $\mathrm{p}<0,05$. Foi utilizado o software Statistical Package for Social Science (SPSS).

\section{Resultados e discussão}

A amostra foi composta por 585 trabalhadores, representando 81\% da estimativa de trabalhadores atuantes no APH do Distrito Federal. Dentre esses, 56 atuavam no serviço aeromédico (9,8\%), sendo $85,7 \%$ homens e com média de idade de 38,9 anos (DP $=5,1)$. Dentre os profissionais com atuação apenas no APH terrestre (529), 70,8\% eram homens e com média de idade de 38,9 anos (DP = 7,4).

Comparando os dois grupos, os trabalhadores do serviço aeromédico apresentaram maior prevalência de homens $(p=0,017)$ e maior tempo de atuação em APH $(p<0,001)$. Não houve diferença entre as idades dos dois grupos.

Em relação aos instrumentos aplicados, os participantes do serviço aeromédico apresentaram para EEPCL escore médio de 3,15 (DP =0,78, IC = 2,93 - 3,36), para ECO escore médio de 3,05 (DP = 2,95 - 3,16) e na IBET média de 3,16 $(D P=0,61, I C=3,00-3,33)$. Para o segundo grupo os resultados para EEPCL escore médio de 3,21 ( $\mathrm{DP}=1,02, \mathrm{IC}=3,12-3,30$ ), ECO com escore médio de 3,08 $(D P=0,49, I C=3,04-3,12)$ e para IBET escore médio de 2,98 (DP =0,66, IC = 2,92 - 3,03). A comparação dos escores entre os grupos indicou diferença significativa apenas para a variável bem-estar no trabalho, com $t(578)=2,20, p=$ 0,03 .

Em termos gerais a percepção dos estressores laborais não foi alta, considerando que a medida varia de 1 a 6 , ficando em patamar similar aos escores na medida de coping, uma vez que teoricamente as estratégias de coping seriam mais demandadas em situações vivenciadas com mais estressoras. Em contrapartida a diferença encontrada em relação a maior satisfação no trabalho para o grupo de trabalhadores do serviço aeromédico potencialmente se relaciona com o grau de especialização desta função e possíveis recompensas simbólicas atreladas, 
como status ou reconhecimento.

\section{Conclusão}

Comparando os trabalhadores do APH atuantes no serviço terrestre com os que também atuam no serviço aeromédico, verificou-se nesses as seguintes características: maior prevalência de homens; maior tempo de atuação em APH; e maior bem-estar no trabalho.

A percepção de estressores psicossociais tende a ser menor quando o compromisso com o trabalho é maior. A partir disso, acredita-se que os profissionais do serviço aeromédico, por precisarem de qualificações adicionais para essa atuação especializada, apresentam maior bem-estar no trabalho e isso minimize a percepção desses estressores. Possivelmente, pertencer a esse grupo especializado seja por si o motivo para maior reconhecimento e satisfação.

A indisponibilidade de estudos com métodos equivalentes sobre os trabalhadores de APH terrestre e do serviço aeromédico limitou a comparação com outras pesquisas.

\section{REFERÊNCIAS:}

BRASIL. Ministério da Saúde. Políticas de atenção às urgências. 3. ed. 2006 Brasília: Ministério da Saúde. Disponível em: http://bvsms.saude.gov.br/bvs/publicacoes/politica nacional atencao urgencias 3ed.pdf Acesso em: 20 fev 2018.

DIAS, Lêda Patrícia Rocha; MENDES, Raylla de Sousa; TRIGUEIRO, Gildenia Pinto; ASSIS, Elisângela Vilar de; FEITOSA, Ankilma do Nascimento Andrade; SOUSA, Milena Nunes Alves de. Enfermagem no Atendimento Pré-Hospitalar: Papel, Riscos Ocupacionais e Consequências Revista Interdisciplinar em Saúde, Cajazeiras. 2016; 3(1): 223-236. ISSN: 2358-7490. Disponível em: https://www.researchgate.net/publication/318642270 ENFERMAGEM NO ATEN DIMENTO PRE-

HOSPITALAR PAPEL RISCOS OCUPACIONAIS E CONSEQUENCIAS Acesso em: 24 abr 2018.

FERREIRA, Maria Cristina; MILFONT, Taciano L; SILVA, Ana Paula Corrêa e; FERNANDES, Helenita Araújo; ALMEIDA, Stanley Pacheco; MENDONÇA, Helenides. Escala para avaliação de estressores psicossociais no contexto laboral: construção e evidências de validade. Psicologia reflexão e crítica. 2015; $\begin{array}{lcc}\text { 28(2): } & 340-49 . & \text { Disponível } \\ \text { http://www.scielo.br/scielo.php?script=sci } & \text { arttext\&pid=S0102- }\end{array}$ 79722015000200340\&lng=en\&nrm=iso\&tlng=pt Acesso em: 18 dez 2017. 


\section{CON

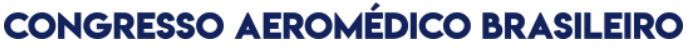

LEITE, Hilda Dandara Carvalho Santos; CARVALHO, Maycon Teyllon Rodrigues de; CARIMAN, Suelky Lilyan da Silva; ARAÚJO, Eronice Ribeiro de Morais; SILVA, Naldiana Cerqueira; CARVALHO, Amália de Oliveira. Risco ocupacional entre profissionais de saúde do serviço de atendimento móvel de urgência SAMU. Enferm. Foco, v. 7, n. 3/4, p. 31-5. 2016. Disponível em: http:// revista.cofen.gov.br/index.php/enfermagem/article/view/912/342. Acesso em: 10/07/19.

LESZCZYŃSKI, Piotr; PANCZYK, Mariusz; PODGÓRSKI, Marcin; KRZYSZTOF, Owczarek; GAŁAZKKOWSK, Robert; MIKOS, Marcin; CHARUTA, Anna, ZACHARUK, Tamara; GOTLIB, Joanna. Determinants of occupational burnout among employees of the Emergency Medical Services in Poland. Ann Agric Environ Med. v. 26, n. 1, p.114-119, 2019. Disponível em: http://www.aaem.pl/Determinants-of-occupational-burnout-among-employees-ofthe-Emergency-Medical-Services,94294,0,2.html doi: 10.26444/aaem/94294. Acesso em 10/07/19.

LIMA, Gustavo Henrique Alves de; SOUSA, Santana de Maria Alves de. Psychological violence in the Nursing work. 2015; 68(5): 535-41. DOI: http://dx.doi.org/10.1590/0034-7167.2015680508i

PINHEIRO, Fernanda Amaral; TRÓCCOLI, Bartholomeu Tôrres; TAMAYO, Maurício Robayo. Mensuração de coping no ambiente ocupacional. Psicol Teor Pesqui. 2003; 19(2):153-8. Disponível em: http://www.scielo.br/scielo.php?pid=S010237722003000200007\&script=sci abstract\&tIng=pt Acesso em: 18 dez 2017.

SIQUEIRA, Mirlene Maria Matias; ORENGO, Virgínia; PEIRÓ, José M. Bem-estar no trabalho. In: SIQUEIRA Mirlene Maria Matias (Org). Novas medidas do comportamento organizacional: ferramentas de diagnóstico e de gestão. Porto Alegre: Artmed, 2014, p. 39-51. Disponível em: http://www.simposio2016. anpepp.org.br/resources/anais/25/1449238191 ARQUI VO GTCulturaorganizacionalesaudenotrabalhoANPEPP2016.pdf 